\title{
11
}

\section{Challenging simplistic notions of outstations as manifestations of Aboriginal self-determination: Wik strategic engagement and disengagement over the past four decades}

\section{David F. Martin and Bruce F. Martin ${ }^{1}$}

This is a practitioners' chapter, focusing on outstations in the Aurukun region of western Cape York Peninsula, and based on our experience spanning nearly four decades. We are father and son: David Martin, now an anthropologist, who established and coordinated an outstation support organisation in Aurukun for some eight years from the mid-1970s; and Bruce Martin, whose mother is a Wik woman from Aurukun, and who in 2011 worked with his community to establish a community-based organisation, Aak Puul Ngantam (APN), focused particularly on developing productive livelihoods on country. The key aims of this chapter are to outline and critically evaluate the principles and practices

\footnotetext{
1 We wish to thank the anonymous reviewers of this chapter, and also Robert Levitus and David Hinchley, for their insightful comments and suggestions. We have incorporated them where in our view they lay within the scope and aims of this chapter, and where they went beyond that, set them aside for further consideration in future work.
} 
of the original outstation project against the concept of 'self-determination', and to contrast these principles and practices with what is being attempted now in a profoundly different Indigenous policy environment. The chapter has arisen as part of a long-term and ongoing engagement and dialogue on such matters between us. However, the first sections on the original outstation movement are largely written by David Martin, and those on APN's work by Bruce Martin. The concluding section of the chapter is jointly written.

\section{Initial involvement: Co-option into Wik life projects}

It was 1975, the reforming Whitlam Government was still in power and along with so many of my (David Martin's) generation, I had been exposed to and deeply involved in political movements such as opposition to the war in Vietnam. I was raised in Brisbane, still a very white town, but in a Quaker family who enjoyed a close friendship with an Aboriginal family in the community of Cherbourg north-west of the city and visited them there. Johannes BjelkePetersen was still Premier of Queensland and P. J. Killoran was the all-powerful director of the Department of Aboriginal and Islander Advancement, and such informal interracial visitation ostensibly still required the approval of the Cherbourg manager. It is perhaps unsurprising that in 1975 I took what was to be a year of absence from my research and teaching as a chemical engineer at the University of Queensland in order to spend the better part of a year travelling around remote Aboriginal Australia with like-minded companions, and that this resulted in a profound change of personal and professional direction.

In July 1975, towards the end of three months spent in Cape York Aboriginal communities as part of this trip, my companions and I arrived in Aurukun. I already had contacts here, including Jonathan Korkaktain, a young man who had previously come to Brisbane for a six-week welding course and who had ended up spending a year living in a house that I shared with a close Quaker friend and others (not altogether inappropriately referred to in the neighbourhood as 'Hippie Hollow'). We camped under big old mango trees near the old Aurukun airstrip, and had a constant stream of Wik visitors, including members of the Korkaktain and other Kendall River families whose traditional lands lay at the very south of the then Aurukun Reserve. The Wik people we met were welcoming, very engaged with and interested in us, and I remember they struck me at the time as politically feisty, assertive, upfront and confident of their rightful place in the world. All around us Aboriginal language was being spoken, and I took tentative steps in learning some basic Wik Mungkan vocabulary. Before the end of our stay, I was told that I had been 'adopted' 
into the Korkaktain family, and was immediately exposed to the practical and moral implications of the Wik kinship system (albeit without, at that point, understanding anything much of its systematic, classificatory and performative character). They, along with other Kendall River families, expressed their desire to move out to their traditional lands - and suggested that I help them do so. More broadly, I was approached to support Aurukun people's opposition to a bauxite mining lease recently issued over a substantial area of the northern part of the Aurukun Reserve by the Bjelke-Petersen Government, without consultation with them or the mission authorities.

It was an intoxicating time for a well-intentioned but naive young Brisbane suburbanite and I had few of the intellectual resources needed to understand the processes by which Wik people were seeking to incorporate me into their own life projects. I knew nothing of Aurukun's history, or of 'classical' Aboriginal cultures, and I had few bush skills to speak of. Moreover, having been born and educated in Queensland, I knew next to nothing about the history of Aboriginal affairs in that State or beyond it, and after all, I was an engineer. But I did think that my engineering education might be useful in conveying the technical implications of bauxite mining to Aurukun people and, with hindsight, I was looking for challenges in life that engineering could not meet. It was a dangerous combination, and I returned to Aurukun after the wet season in 1976 to work on the bauxite mining issue. However, I was soon recruited by Kendall River families to move with them out bush, initially to their staging post of Ti-tree outstation some $15 \mathrm{~km}$ or so north of the Kendall River, where we spent the wet season alongside Ti-tree families (in my case under a tent fly), before we eventually moved in the dry season of 1977 to Kuchenteypenh, a few kilometres upstream from the mouth of the Kendall River (see Map 11.1). 
EXPERIMENTS IN SELF-DETERMINATION

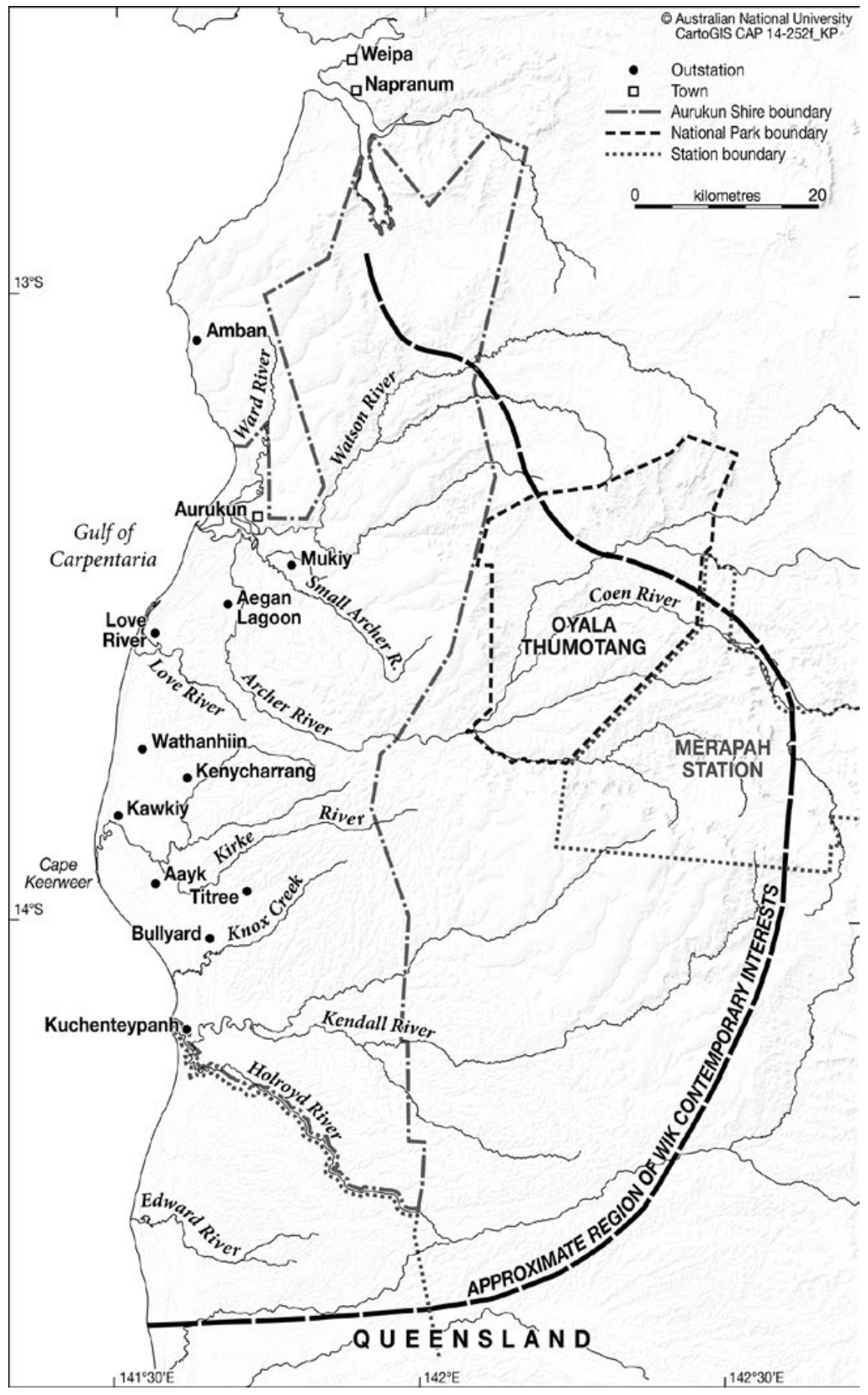

Map 11.1 Aurukun outstations.

Source: Karina Pelling, CartoGIS, ANU College of Asia and the Pacific 
I lived at Kuchenteypenh for close to a year, along with about 40 north Kendall people and, for much of this time, an adventurous younger sister who had come to join me. South Kendall families and others established a small outstation across the river, at Kuli-anychen. Although an outpost of the Aurukun Mission run by Wik missionary workers had been established a few hundred metres from Kuchenteypenh in 1928 and had existed until the late 1950s, there was no infrastructure whatsoever when we arrived. Over the course of that dry season, we built basic shelters, sank a well, set up a solar-powered radio communication system with the mission authorities at Aurukun, and started clearing by hand an $800 \mathrm{~m}$ airstrip on a sand ridge a couple of kilometres away. It is a rich environment - just upriver from the Kendall estuary with extensive mangrove forests, pericoastal ridges with vine thickets and freshwater swamps. We lived well according to the season, variously on fish, stingray, estuarine sharks, crabs, ducks, wallaby, wild pigs and occasional stray cattle, with some bush foods such as yams. These were supplemented by stores brought down on a precarious journey around the coast on a small mission boat and eventually overland, comprising particularly of flour, sugar, tea and powdered milk, syrup and jam and, very importantly, tobacco, cigarette papers and matches, with the hunting and fishing made possible by fuel, fishing lines, hooks, sinkers and ammunition.

A number of languages were spoken at the Kuchenteypenh outstation, including what I now know to be Wik Ngathan, Kugu languages by those from south of the Kendall, and the lingua franca of Aurukun, Wik Mungkan. This multilingual situation complicated my learning Wik Mungkan, but I persevered with it, slowly gaining competence in everyday communication. Learning by experience, always to be careful to defer to older men, and in particular to the eldest of my Korkaktain brothers on whose country Kuchenteypanh lay, I nonetheless found myself drawn into mediating conflicts, and was considered responsible for organising matters that required cross-family cooperation or that serviced the outstation as a whole. These included operating the radio schedule with Aurukun, including ordering food and other items from the mission store, eventually running a small independent store at Kendall itself (as did Peter Sutton at Peret to the north), and along with my eldest brother, initiating work on conjoint activities such as clearing the airstrip and the track to it. Sutton (2009: 171-5) has written of similar experiences of his time at Peret outstation, now referred to as Wathanhiin.

To this point, basic support for the outstations then established (largely Peret, Ti-tree and, more latterly, Kendall River) was being provided by staff of the Aurukun Mission. In 1978, I moved into Aurukun itself to establish a distinct support service for outstations, as there were significant numbers out bush at Peret and Ti-tree, and there were increasing numbers of Wik people seeking 
support to move out bush and establish other outstations. I will discuss this stage below, but first it is necessary to briefly outline certain factors that were relatively unique in the Queensland context, and which were preconditions to the establishment of and support for outstations in the 1970s, largely in the Aboriginal lands south of Aurukun.

\section{Preconditions for the 1970s outstation developments in Aurukun}

Peter Sutton (this volume) has detailed a number of the factors that preceded the establishment in the 1970s of outstations south of Aurukun between the Archer and Kendall rivers. Here I will complement his discussion by briefly outlining a set of factors that in my view were significant in creating the preconditions for Aurukun's outstations in this period.

The first concerns an intersection between geography and the particularities of the history of the Aurukun Mission. While the township of Aurukun itself lies some $600 \mathrm{~km}$ north-west of Cairns and only $80 \mathrm{~km}$ or so south of the mining township of Weipa, its location close to the coast on western Cape York, with its monsoonal climate and large serpentine rivers winding their way down to the Gulf of Carpentaria, rendered it essentially inaccessible except by air and by boat. Only in the 1980s, with the construction of an unformed road linking Aurukun with the Peninsula Development Road running to Weipa, was Aurukun itself accessible overland - at least during the dry season. The extensive area between the Archer and Kendall rivers - part of the Aurukun Aboriginal Reserve - was even more remote and inaccessible, both from Aurukun where it necessitated an $8 \mathrm{~km}$ boat trip upstream to a precarious landing on the south bank of the river, and from the east where the only access until the mid-1980s was by a rough bush track following the south side of the Archer from Merepah Station west of Coen. This isolation rendered the movement of people between Aurukun and the developing outstations and the logistics of outstation support complex and resource intensive, but historically had insulated its population from many of the pressures of the colonial expansion into Cape York.

This geographical insulation was reinforced by the Reverend William MacKenzie, a Presbyterian missionary and the superintendent of the Aurukun Mission between 1923 and 1965, who strictly controlled access by outsiders. MacKenzie was tough, authoritarian and meted out harsh punishments to those who broke the rules or challenged his authority, including cruel floggings and, for some, banishment to Palm Island. Children were raised in separate boys' and girls' dormitories, from which the boys left to work on cattle stations in Cape York and beyond or in the bêche-de-mer fishery in the Torres Strait, while the 
girls left to do domestic work around the mission and marriage. At the same time, MacKenzie (along with his wife, Geraldine) appears to have supported the maintenance of aspects of Wik culture and practice, both philosophically and practically. He encouraged the use of language (outside of the fenced-in mission buildings) and the maintenance of male initiation, and was himself put through the first stage known as uchanam.

If partly for economic reasons, since the Aurukun Mission was starved of funding from the Queensland Government, MacKenzie required the families of children in the dormitories to bring in food they had hunted or gathered in the surrounding region, and until the early 1960s newly married couples were sent to live out bush for several months. Furthermore, while MacKenzie very actively sought to bring children into the dormitories in Aurukun, he did not force people to settle there. Consequently, in the mid-1970s, many of the senior generations of Wik people whose traditional lands lay south of the Archer River would have lived out bush for extended periods of their lives, and a number of their children (now young adults and middle-aged) were born out bush. Additionally, the Aurukun Mission established a cattle industry, largely south of the Archer River, which reached its peak in the 1960s, and whose workers were almost entirely Wik people. It was centred on Peret outstation, but created a number of hubs that formed the basis of subsequent outstation development - apart from Peret itself, most importantly Ti-tree, but also others such as Kenycherreng, Bamboo and Hagen's Lagoon. Peret and Ti-tree in particular had quite significant infrastructure, including airstrips, rudimentary water supplies, sheds and (in the case of Peret) what was by the mid-1970s a rather dilapidated homestead.

A consequence of these historical and geographical factors was that in the mid1970s the traditional countries of a significant majority of Aurukun's residents had never been legally alienated since they lay within the southern portion of the Aurukun Reserve, and many of that majority had maintained connections to, and had a detailed knowledge of, the cultural geography of that area and of their own estates within it - although as I found when living there and as Sutton (this volume) shows, those connections were far from uncontested. That knowledge was subsequently documented in the comprehensive anthropological mapping of the region by Peter Sutton and to a lesser extent myself, John von Sturmer and others (Sutton et al. 1990), which formed the ethnographic basis on which the first stage of the Wik and Wik Way native title claim was determined in 2000.

Other factors were also at play. The history of Aurukun after the MacKenzies left in 1965 was one of increasingly relaxed controls by liberal mission authorities (for instance, the dormitories were closed the next year), intensifying exposure to the secular institutions and agencies of the outside world, and accelerating 
changes in the circumstances of Wik people's lives, much of it profoundly detrimental (Martin 1993; Sutton 2009). The generally liberal character of the mission administration post-MacKenzie had two interrelated effects of significance to this account. The first was that the political and administrative 'glue' under the authoritarian MacKenzie regime that bound the relatively culturally homogenous but deeply segmented Aurukun population quickly eroded, allowing the omnipresent but hitherto largely suppressed competition and conflict between and within various levels of Wik groupings to surface. The second was that in its final decade or so of administering Aurukun, the Presbyterian Church's Board of Ecumenical Mission and Relations (BOEMAR) placed increasing emphasis on self-management at the broader community level through the Aurukun Aboriginal Council, but also provided support for the expressed aspirations of groups from south of the Archer River to establish outstations on or near their traditional country. It is significant that the moves to establish Aayk and Peret, Ti-tree and the two outstations on the lower Kendall River, as well as in subsequent years Kenycherreng, Bullyard (Am - the Wik name) and Walngal (see Map 11.1), involved individuals from groups who had largely been excluded from holding power in the interface between the mission and Wik - a phenomenon reported in other regions (for example, Gerritsen 1982).

From the early 1970s, at the Federal level and influenced by H. C. Coombs, there were moves towards a policy of self-determination for Aboriginal people. For the Wik groups who initiated the move to establish outstations, however, the incentive to decentralise (as expressed to me) lay more with a desire to be self-determining vis-à-vis those other Wik they perceived as controlling Aurukun. Not unrelated to this was the wish to remove themselves from the increasing conflicts within Aurukun itself, rather than to be independent and self-determining vis-à-vis the wider Australian society. Indeed, there was a pivotal role played by a small set of non-Wik individuals, of whom I was one, in the development of the Aurukun outstations in the 1970s. These were all individuals who were strategically incorporated into Wik kin networks to serve Wik ends and access desired services and resources. They were the anthropologist John von Sturmer, in the region first in 1969, with deep links into Kugu groups from south of the Kendall River; anthropologist Peter Sutton, who undertook his doctoral field research at Peret from 1976 and played a major role in the establishment and life of that outstation in its earlier years (see Peter Sutton, this volume; and Sutton 2009); the Reverend John Adams and his wife, Jeanie, who had particularly close links with Ti-tree families and lived at the outstation there before moving in to Aurukun for wider community development work; and myself in relation to Kendall River people as outlined above, and subsequently in the development of an outstation support service as described below. 


\section{The Aurukun Outstation Support Group}

The Aurukun Outstation Support Group was a non-incorporated resource centre independent of, but supported by, the BOEMAR administration, which I established when I moved in from Kuchenteypenh in 1978 and coordinated until I left in September 1983 to undertake a Masters degree in anthropology in London. Here, I will outline the methodology and philosophy of the resource centre, my own roles and my assumptions and expectations at that time, and the challenges to those assumptions and expectations posed by my everyday experience.

The support group grew quite substantially over the period to 1983, although it never had more than six or so staff. It aimed to be collaborative, but looking back, it was most definitely driven by me. I worked almost entirely in Wik Mungkan, and the only other non-Wik full-time employee was our mechanic, Bruce Hinchley, originally a prune farmer from near Young in New South Wales who could do truly extraordinary things with broken-down machinery of all types - a very necessary skill, as I shall discuss below. Wik male employees worked at tasks such as vehicle and boat drivers, logistics organisers, mechanic's assistants and bush builders. Initially, the support group transported food, fishing gear, ammunition and so forth, which outstation residents ordered over the morning radio schedules and which were filled by the Aurukun store. However, this was quite expensive and we ended up ordering in bulk directly from suppliers in Cairns, as I had done for the little store at Kuchenteypenh and Peter Sutton had done for its equivalent at Peret.

The support group was organic, evolving in its size, focus and complexity over time. In terms of contemporary practice and expectations, its governance would have been seen as highly deficient since it had no formal mechanisms for 'community' oversight of my work - for example, through an Aboriginal board. As I saw it at the time, my accountability was maintained through the everyday praxis of engagement with the Wik individuals and families, who were never loathe to let me know if they felt I was not being accountable to them, or was not being equitable in the allocation of support services.

At its peak in the 1978 and 1979 dry seasons, the support group serviced about 300 people on outstations south of the Kendall River, and a smaller but still substantial population in the wet season. Its focus was very much on providing the basic logistics and infrastructure to support individuals and family groups to move out to and stay on country for as long as they desired. Transport was central, and was highly seasonal; as observed above, this was a remote and inaccessible region, with most of the outstations on ridges in the extensive coastal floodplains that were intersected by river systems draining west to the Gulf 
of Carpentaria. In the dry season, four-wheel-drive vehicles and tractor-trailer units were used to transport food and necessities such as building materials and fuel, along with passengers. The support group provided subsidised transport for teachers, nurses and other service personnel to visit outstations, and for emergency evacuations by plane.

In order to get vehicles, stores and supplies across the Archer River and upstream from Aurukun, we designed and constructed a flat-bottom barge. In the wet season the only practicable access to all but the Kendall River outstations was by light aircraft, and eventually a charter company had a specialist twinengine light aircraft permanently stationed in Aurukun for outstation support. Peret and Ti-tree already had serviceable wet season airstrips from the cattle days, but at the newer outstations of Kuchenteypenh, Kenycherreng, Bullyard and Walngal, airstrips were laboriously cleared using chainsaws, axes, picks and shovels by outstation residents, with some assistance from support group staff such as myself.

This was a very resource-intensive (human and capital) transport system, and although the support group received a Federal grant through the then Department of Aboriginal Affairs (DAA), this was not sufficient for the volume and complexity of transport requirements. To meet the demand, we therefore leveraged the DAA funding by negotiating and instituting a 'user pays' transport system, charging reasonably nominal seat prices for planes (varying between $\$ 20$ and $\$ 30$ per adult according to the distance from Aurukun), as well as for overland transport in the dry season, and for personal freight such as foodstuffs. More generally, a key principle in the operations of the support group from its inception was to encourage and support people's own initiative and self-reliance rather than simply providing services on demand. For example, we attempted to avoid getting caught up in the interminable politicking about country conducted within the township of Aurukun itself, including attempts to capture support group resources for symbolic rather than practical ends, manifested, for example, in demands for infrastructure to be put in place before people would move out.

An important operating principle was the requirement for people to demonstrate some commitment to spending time out bush before the support group would provide more than transportation in the way of assistance. For those moving to areas without existing infrastructure, we provided basic building materials such as corrugated iron and some basic tools, but in general where there were able-bodied men in the group they were expected to undertake the work themselves. As noted above, however, I and other support group staff assisted outstation residents in major tasks such as clearing airstrips, digging and lining wells, and on some occasions in constructing their basic huts of bush timber and corrugated iron. We also managed a radio communications system that was 
used to organise transport requirements from and between outstations, ordering foodstuffs and other necessities for delivery to outstations, organising technical assistance such as a mechanic to repair outstation equipment, and for contacting Aurukun in emergencies. Outside the morning schedules each weekday, the radio system also served for communications between kin living in different outstations.

With hindsight, it is clear that the issue of the social and economic sustainability of outstations was looming large almost from their inception, although I understood this only incompletely at the time. There are several factors relevant to this. First, as I was to find out, I was absolutely central to the everyday operations and the social sustainability of the Outstation Support Group. Despite subscribing to the 'working myself out of a job' mantra of community workers of the era, it became transparent over time that Wik people by and large were focused on keeping me working in my job (see also Peter Sutton, this volume). I was told quite explicitly by senior Wik outstation residents that they strongly preferred me rather than a Wik person to manage outstation support, because (as they expressed it to me) no Wik person could be 'fair' in allocating resources, time and support among the various outstations and family groups.

There was also no recognition - by myself or others who supported the Aurukun outstation movement, including its bureaucratic patrons in the DAA - of any need to develop local economies or productive livelihoods. The goal was moving 'back' to country and thereby reducing conflict and revitalising traditional ways. There was uncritical affirmation of the importance of hunting, fishing and to a much lesser extent gathering as valued and valuable activities that improved health and maintained traditional skills - although the cattle industry was revitalised for a while by the Aurukun Community Incorporated (ACI) in the mid-1980s and provided some local employment (as well as opportunities for significant rent-seeking by some individuals on whose country the ACI enterprise operated).

I earlier expressed the view that the impetus for people moving to outstations arose as much from the conflict and politicking among Wik in Aurukun as it did from a desire to exercise self-determination vis-à-vis the wider society. Its motivating force therefore was dependent on a social calculus among Wik in which the benefits, resources and opportunities associated with living on or establishing an outstation-importantly including significantly lower levels of conflict and violence- outweighed the disadvantages. It became clear that the factors underlying this calculus among the senior generations, who had coopted Peter Sutton, John and Jeanie Adams and me into this enterprise, were not being reproduced in the succeeding generations, along with much else of Wik classical culture. As discussed later in this chapter, for younger generations 
of Wik there was an increasing disengagement from intimate connections to a deeply cultural landscape in parallel with a progressive engagement with a very different kind of life in the township of Aurukun itself.

Certainly, there were large numbers of people out on country in the late 1970s and early 1980s, particularly at Peret and Ti-tree - but this then exacerbated conflict at those outstations, particularly Peret. Furthermore, after the euphoria of the initial moves had faded, as I found at Kuchenteypenh, and after basic infrastructure had been established, there was not much to keep people engaged. The 'relentless boredom' of which Sutton (1978) wrote became a real factor. This was particularly an issue for younger people, who were highly mobile anyway and who drifted back into Aurukun, drawn there by its excitement and intense sociality. By the early 1980s, the demographics of most outstations as I recall it were comprised largely of older people, in some cases along with their young grandchildren.

There was another aspect of the work of the support group that reflected systemic issues with sustainability, and exercised me greatly in my role as coordinator. This concerned the way in which outstation services and equipment were used and abused: the radio communication system, vehicles, tractors, outboard motors, and so on. While not universal across all outstations, there was what I experienced as a widespread fecklessness and unwillingness among young men in particular to exercise responsibility in the use of equipment along with resources such as scarce and expensive fuel. One issue was misuse of the radios. There were numerous occasions when an emergency call to Aurukun would request a plane be sent to collect a sick person (often a child). There had been deaths on outstations, including two at Kuchenteypenh while I was living there, and there were no means at the time to get sick individuals back to Aurukun for treatment, so we were certainly very aware that serious problems could arise. If a Wik staff member took the emergency call, there was no way he could or would query the legitimacy of a demand for a plane be sent out; an assertion of illness axiomatically commanded support and sympathy, or risked blame and potentially severe sanctions should the individual concerned prove to be genuinely ill. If I took such a call, I would try to get a sense of the seriousness of the situation, but without medical training (or authority), I always erred on the side of caution. Many emergency calls, however, ended up not being emergencies at all, but appeared to me to be convenient ways for people to get back into Aurukun; not infrequently, the supposedly ill person would not even present at the Aurukun clinic.

Tractors were a particular problem. As a result of earlier DAA support for outstations, most groups had been supplied with a tractor-trailer unit, a number even before moving out bush. It was thought that these would be suitable for the very rough country (which proved to be the case) and robust enough to 
withstand the rigours of use for outstation transport (which proved not to be so). On multiple occasions, we were called to extricate or repair tractors that had become badly bogged or inundated on tidal flats, or which had a rear tyre irreparably staked by the timber used to try to extricate it from a bog, or which required a major engine rebuild because of failure to clean filters, or because of contaminated fuel, or which had just been abandoned because it could no longer be started.

The question of who had control of an outstation tractor was a major source of conflict in itself on some outstations, and senior Wik had little control over young men commandeering the outstation tractor for their own purposes, including on occasion to return to the landing on the Archer River from which to go back into Aurukun. Young men would break into the boxes in which the radio communications batteries - charged by solar panels - were secured, in order to use them for Toyotas or tractors whose batteries had been flattened by multiple unsuccessful attempts to start them. This would then leave the outstation without the ability to radio for assistance and without transport. The costs of repairing damaged equipment became beyond the capacity of the support group to manage, and in the case of tractors we instituted a regime where we would not repair one until there was agreement that it would subsequently only be driven by designated licensed drivers, and that the outstation would be responsible, paying for an hourly charge-out rate as measured by meters we installed on repaired tractors. This of course did not prevent misuse, but it did provide a culturally acceptable means for senior outstation people to at least attempt to dissuade young men from misusing the tractors, and at Kenycherreng (where there was a smaller and more solidary group with relatively clearly defined lines of authority around everyday affairs) it proved remarkably successful.

With the benefit of hindsight, and informed by anthropological understandings, I now see the nexus between the immediate consumption and use by Wik of (objectively) scarce resources (finances, fuel, equipment and so forth) on the one hand, and on the other the unrelenting pressure from demands on me and on other non-Wik staff, less adept as we were at evading such demands than the Wik men working for the support group. Both were ultimately unsustainable in light of available funding sources and personal capacities respectively, but both can be understood as forms of demand sharing (Peterson 1993), through which Wik opportunistically sought both tangible and intangible resources from others as aspects of what is still in many ways a 'foraging' economy (Martin 2011: 206). Of course, this was a system with me at its centre, which, in very large part, was my own creation. But I can now clearly see that this was a collaborative project to which Wik themselves actively contributed - a project of 'agency through dependency' in which Wik (as individuals, and in aggregations of various forms) 
sought to access both material and symbolic resources and strategically leverage relative advantage within a highly contested Wik polity through intermediaries or brokers such as myself (see also Sutton 2009).

As it came close to the time for me to leave Aurukun in September 1983 to study in London, the Uniting Church sourced a replacement coordinator. However, he had no experience in Aboriginal affairs or life in a remote community and lasted only a few days before having to be evacuated out of Aurukun. Outstation support was then taken over by ACI, which over the next few years made quite significant investments in outstation housing and other infrastructure in a number of locations. However, the capital investment by ACI in outstation infrastructure seems to have been in inverse proportion to the social investment by all but a few Wik in residing on outstations, and by the time I arrived back in 1985 to begin my doctoral field research, barely any Wik lived out bush.

\section{Strategic engagements and disengagements}

It is no coincidence that the gradual abandonment of most outstations coincided with very significant changes in Aurukun itself. The foundation for these changes was set by the 'takeover' of the Aurukun Mission administration by the Queensland Bjelke-Petersen Government in 1978, and the imposition of a form of local government under a compromise brokered by the Federal Fraser Government (Martin 1993: 3-5). Outstations in particular had aroused very strong opposition from the Bjelke-Petersen Government and from Killoran, the powerful director of the Department of Aboriginal and Islander Advancement, whose expressed policy at this stage was still one of assimilation of Aboriginal people into mainstream society. Departmental officers, the State police and informants such as barramundi fishermen conducted both covert and overt surveillance of Aurukun outstations and supportive mission staff such as John and Jeanie Adams during this period-part of general Bjelke-Petersen Government attempts to keep 'radicals' and their ideas out of Aboriginal communities.

The imposition of local government marked the beginning of profound changes in Aurukun. From a poorly funded and relatively simple organisational structure with a limited number of staff working for agencies actually present in Aurukun, and with comparatively clearly defined policies and practices, there quickly developed a complex (albeit ineffectual) administrative system, with a greatly increased number of non-Wik people living in Aurukun and working for the numerous agencies and organisations, and a massive increase in funding levels. The new breed of staff, by and large, were of a different order from those who had been there in the days of the church-run administration-totally 
unconcerned with how Wik people thought or with their worlds of meaning, and only with (ostensibly) delivering services. Those services, however, did not include outstations: successive council administrations made it clear that they would focus on the town of Aurukun itself and provide at best very limited assistance to outstations.

Concomitantly with this increasing administrative complexity, Aurukun people have been exposed ever more directly to the forms and institutions of the wider state: construction of an access road through to the Peninsula Development Road that was open for all but a few months of the year, the full introduction of a cash-based welfare economy, within a few years the opening of a liquor outlet in what had been up to that point a training centre, consumer goods, telephones and televisions, ever greater numbers of outsiders living there or passing through - all of which meant that while remote, Aurukun was no longer isolated. This period has been one of quite profound social, political and economic transformation in Aurukun; it has seen a progressive escalation of social problems such as very high levels of interpersonal violence, widespread alcohol and other substance abuse, increasingly troubled and often angry and alienated younger generations, and major health issues, such as high rates of diabetes and alcohol-related morbidity (Martin 1988, 1993, 2009; Sutton 2009). The increasing social dysfunction in Aurukun has in turn led to ever greater interventions by the courts and the legal system, and by other agencies and programs of the state (Martin 1993, 2009).

Aurukun people had come to national attention through the 1970s and into the 1990s through their feisty spokesmen and women, and their willingness to take collective political and legal action to defend their collective rights (for example, in opposing the 'takeover' in 1978, and in the early 1990s through the Wik native title claim). In contrast, more recently Aurukun has received unwanted (and resented) national prominence through its reputation for high levels of internal violence, alcohol abuse, destructive behaviour by young men, and other manifestations of a deep social malaise. The worsening circumstances of everyday life and its increasing atomism as social problems escalated - and as institutions of the state have established an ever greater presence in Aurukun, both required and legitimated by these very problems - have been paralleled by an increasing disengagement by many Wik from working to address the circumstances of their lives, whether at the individual, family or broader collective levels (Martin 2010).

The establishment of the Aurukun Shire Council created a new and powerful political institution, greatly expanded resources and new fields of endeavour for enterprising Wik politicians. Wik were as pragmatic as ever; despite the national campaign against the 1978 State Government takeover supported by the Uniting Church and involving many prominent senior Wik people, before long 
the council itself was front and centre in Wik politics and involved most of these same individuals. The dramatic transformation of life in the township of Aurukun itself, while frequently involving high levels of chaos and violence, also provided upcoming generations of Wik with a new and all-pervasive focus for life and meaningful action quite radically sundered from that which had underpinned the original rationale for outstations. During my own time in Aurukun and its outstations, I observed a radical deskilling, in terms of both the classical Wik world and the kinds of endeavours that the mission had focused on.

I also observed a quite profound involution in Wik life worlds. As I noted earlier, when I first encountered Wik in the 1970s, Wik people had a markedly ethnocentric and self-conscious view of themselves as the bearers of traditional culture in Queensland, but were also vitally interested and engaged in the wider world. Over the next decades, Wik increasingly turned inwards, with passion and energy devoted to the interminable inter-family feuds that paralysed life in Aurukun for days at a time (Martin 1993). I found among younger men and youths in particular widespread hostility both to 'classical' expressions of Wik culture and to what the wider society might offer. Many were angry, alienated and suffered major alcohol and other substance abuse issues.

Thus, there have been parallel processes of the progressive disengagement of Wik people (especially younger generations) from intimate connections to country on the one hand, and on the other engagement in the rapidly deteriorating life in the Aurukun township. Country has become more and more the focus of identity politicking within Aurukun itself for all generations, rather than of everyday lived experience, and knowledge of country has become progressively more attenuated. These factors - pervasive through many parts of remote Australia, in my experience-have profound implications for how we might envisage the project of realising certain forms of self-determination through outstations today within communities such as Aurukun.

\section{New paradigms from the old: Productive livelihoods on country?}

I (Bruce Martin) spent much of my early childhood between Aurukun and its various outstations and beyond them, as part of my father's ethnographic work with Wik families. The role he had played in outstation development, and ultimately in assisting Traditional Owners to record areas of cultural significance to them, had a profound impact on the way other Wik people viewed me. Members of the Korkaktain and other Kendall River families had always seen me as a Kendall River person, and reckoned their kin relationship to me through my 
father, as opposed to through my Wik mother. I was in a unique position from an early age in that I was 'within' the Wik system, both through my mother and through my white father, but was simultaneously seen as having a place 'outside' this system as well.

In 2009, I was partway through a Bachelor of Arts through the University of New South Wales, but by mid-year was fielding telephone calls from family back in Aurukun who were concerned about a recent declaration by the then Bligh State Labor Government of the entirety of the wetlands across the Archer River Basin and south to the Kirke River Basin as a High Preservation Zone under the Wild Rivers Act (Qld) 2005. This was essentially the area within which most of the outstations lay and within which the lands of the majority of Aurukun's Wik people were situated, and included my mother's country. My mother's family asked me to come back to Aurukun to help them make sense of it all, and to find out what impacts the declaration would potentially have on people's aspirations for their country. This included me spending three months based at my aunt's outstation on the Archer River, Stony Crossing. What I had known to be true (but had not realised its scale) was just how empty the outstations were to the south of Aurukun. As a boy, I had spent time visiting and living on various outstations and homelands, and at the peak of the community company ACI, some 350 Wik people lived on their homelands over a dry season. When I was there for three months in 2009, I was the only person out there.

The Wild Rivers Act issue forced Wik people from the region subject to the declaration to consider what 'country' meant to them, and what it might mean to succeeding generations, and raised questions about their ability to pursue sustainable development opportunities. The Wild Rivers legislation and declaration acted like a catalyst for Wik people to have in-depth conversations about what role they wanted to play in the continued management of both cultural and biodiversity values of their own lands. With the assistance of some external agencies, individuals and the Cape York regional organisations, we initiated a process of mapping people's own aspirations for country, family group by family group, based on their potential roles in the management of its cultural and biodiversity values, as well as economic opportunities. After more than 15 years of fighting for our native title rights through the Wik claim, the Wild Rivers declaration had shifted the focus to the right to (and need for) sustainable use and development of our lands, and therefore how to create development opportunities from our native title rights. My father used to joke with me that native title only entitled us (Wik people) to be native. This same argument around development was articulated in a very different way by the head of my own family group and ceremonial head of my broader clan group, Silas Wolmby. During our aspirational social mapping and planning processes in late 2009 and into 2010, Silas said to me: 
Our old people looked after this country, story place, sacred site, hunting and fishing ground. In return, that country looked after us and our families, gave us food and water, shelter, and looked after us spiritually. We are just trying to do that same thing today, look after that country so it looks after us.

During the initial engagement process, Wik people were asked whether they wanted a regional organisation to auspice the Federal Government funding that was initially offered. The very clear message that came back was that they would prefer to discuss and plan for a longer period to be able to develop a strategy that ultimately meant they had genuine ownership of the governance structure that was created and, ultimately, the outcomes that were achieved. What I understood from this was that - more than the outcome being achievedwhat was most critical to Wik people was genuine input into the decisionmaking processes to achieve that same outcome.

A critical matter arising out of these detailed consultations was the need to build an appropriate governance structure around the aspirations expressed. This was ultimately articulated as establishing a framework to:

- assist Traditional Owners to get back to country

- assist Traditional Owners in the transfer of knowledge to younger generations

- maintain the cultural and environmental diversity of Wik and Kugu groups

- promote economic and training opportunities for Wik and Kugu people

- promote social programs to improve health and education outcomes for Wik and Kugu people.

These objectives are reflected in the constitution of the community-owned organisation I helped establish, Aak Puul Ngantam Limited (APN Cape York), and in the projects we have initiated. From the beginning, APN had a clearly articulated aspiration to reduce our dependence on government funding (while recognising it would remain essential to achieving the goals set for it, and that meant building enterprises). The philosophy was that it was impossible for us as Wik people to be environmentally, socially or culturally resilient without also being economically resilient - and that meant working to diversify APN's income streams to manage the risk of market changes and the inherently risky circumstances of enterprises in this region. We never underestimated the social and financial challenges in achieving this. During the Wild Rivers debate in Cape York, at a community meeting, I heard one old pastoralist say, 'It's hard to be green when you're in the red', to which I replied, 'It's even harder to be green when you're in the red and you're black'.

In the work APN and its partners did and the conversations that were facilitated, it was interesting to see the shift in language and thinking around productive livelihoods on country. There was an explanation APN developed for Wik 
people around the principles of market economics, in terms of putting in labour, utilising deep cultural knowledge of seasons and country, and being able to bring all of these together to provide for oneself and one's family. There was also a general understanding of this in the context of Wik art and crafts, and of course cattle-rearing. There was a service or product that Wik people had and were able to provide, and this was worth something in the outside world. The benefit of these services and products for Wik people was that it linked aspiration with opportunity and brought dollars from outside the Wik system into the community - dollars that were relatively untied to government. These sustainable livelihoods on country that people had mapped out as part of their aspirational planning and that external advice had shown to be a potentially viable enterprise also helped to establish, for some, an alternative to the 'relentless boredom' referred to earlier. The ultimate aim of APN was to have a diversification of revenue streams that would help mitigate seasonality and market volatility but which were primarily focused on outstations and would require people to be on country for periods - whether it was for a week as part of a weed-spraying program, for a couple of months for feral pig control and associated turtle nest management, or indeed for most of a dry season for families wishing to be near their kin working on country.

Thus far, APN has had some success in achieving its goal, but the difficulties of its operating environment have certainly been demonstrated. Perhaps its most notable success was in attracting a substantial six-year investment from the Biodiversity Fund established by the previous Federal Government. This is focused on such matters as feral animal and weed control and sea turtle nest monitoring and protection, and has provided important multi-year baseline funding for the Wik and Kugu Ranger Service. One component of this has involved the removal of feral cattle across the region between the Archer and Kendall rivers to reduce their impact on that region's very significant cultural and biodiversity values. This in turn has allowed APN to establish the beginnings of an appropriate-scale cattle enterprise, building up an improved quality herd over suitable areas. Funding for this has been an amalgam of cattle sales, and philanthropic investment through a combination of loans and grants, which have also allowed fences to be constructed and some basic infrastructure to be put in place. Cattle have an important role in the history of Aurukun; as noted earlier in this chapter, during the mission era, many Wik men were sent to work on cattle stations throughout Cape York and beyond, and there was a cattle industry during the mission period, re-established by ACI in the 1980s. The establishment of a cattle enterprise was one of the key themes emerging from our family consultations, but the very clear message was that it needed to be both commercially viable and culturally and environmentally sustainable. The work APN has done to date with key partners such as the Commonwealth Scientific and Industrial Research Organisation (CSIRO), Indigenous Land 
Corporation, Indigenous Business Australia and the Queensland Department of Primary Industries (DPI) has allowed us collectively to better understand where this balance might sit.

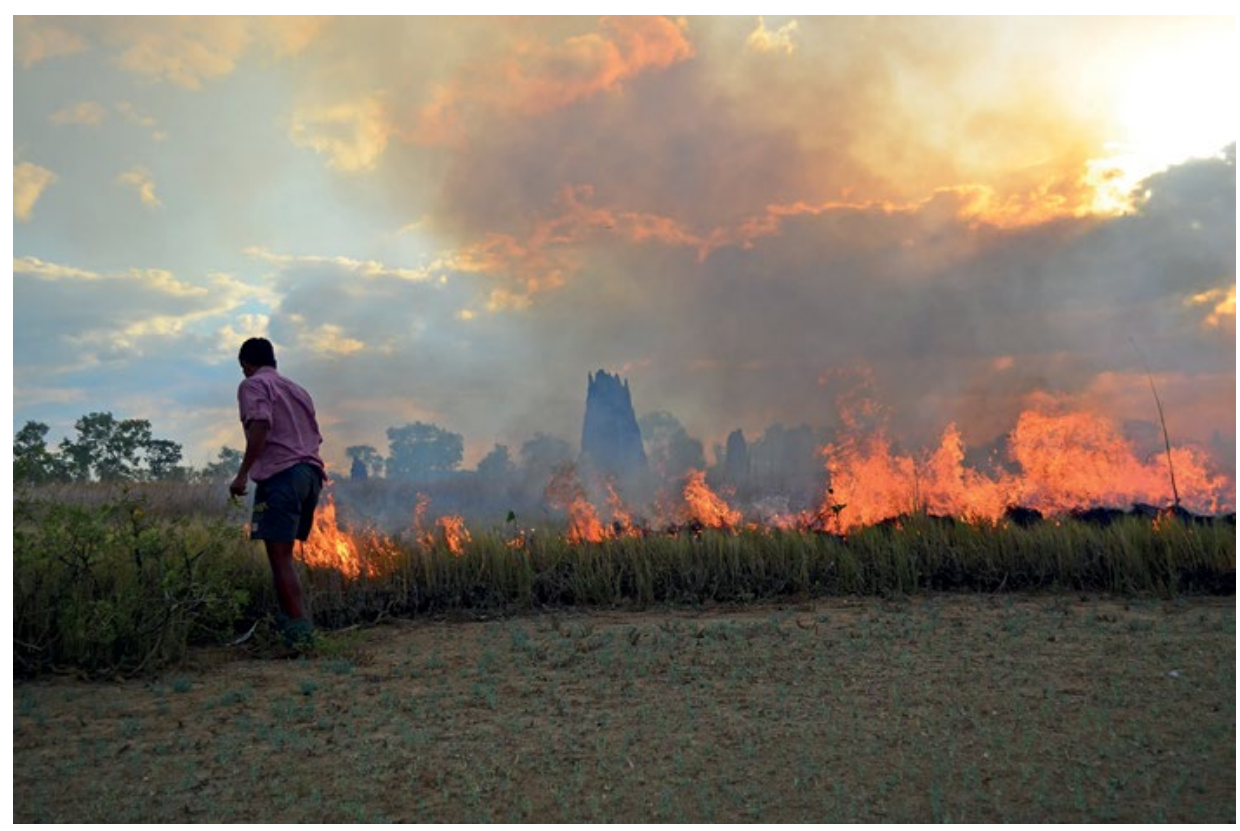

Figure 11.1 Wik and Kugu Rangers burning open floodplain country near the Kirke River, south of Aurukun, as part of their fire management and carbon abatement strategy. In 2015, APN received its first carbon abatement payment, quantified through a research partnership with the CSIRO.

Photo: Rex Martin

Experience thus far has shown that as a stand-alone operation, multiple factors including the distance from markets mean that a cattle enterprise based entirely on Aurukun lands is unlikely ever to be a major source of income, but that it does have the potential for delivering local social benefits as well as important synergies with other activities on country, including increasing people's ability to access and use outstations in the absence of government funding. Another instance of where local knowledge and aspirations can be brokered around market and environmental services opportunities can be seen in the work conducted thus far by APN on a carbon-farming initiative. APN had established research collaboration with the Northern Australian Indigenous Land \& Sea Management Alliance (NAILSMA) and CSIRO to inter alia measure the biodiversity outcomes and quantify carbon abatement from a managed mosaic burning regime conducted collaboratively with the APN Rangers across the sclerophyll forest sectors of Aurukun lands. As mapped by DPI, these areas 
do not support viable numbers of cattle, but with the work APN is doing with its partners on carbon abatement, the evidentiary basis suggests that this may be another diversified income stream.

APN has also assisted the Aurukun School with 'culture camps' out on country, and has assisted with youth programs in Aurukun. Much like my father and other outstation workers in the 1970s and 1980s, and indeed myself over the past few years, APN acts as a conduit between the aspirations and opportunities people have to access their country and the information, systems, partners and resourcing that are required to better understand and ultimately realise these aspirations. In 2013, APN assisted more than $400 \mathrm{Wik}$ people to return to their traditional lands, and for many of the younger generation, to see it for the first time. For most it was for a few days; for others, for the entirety of the dry season.

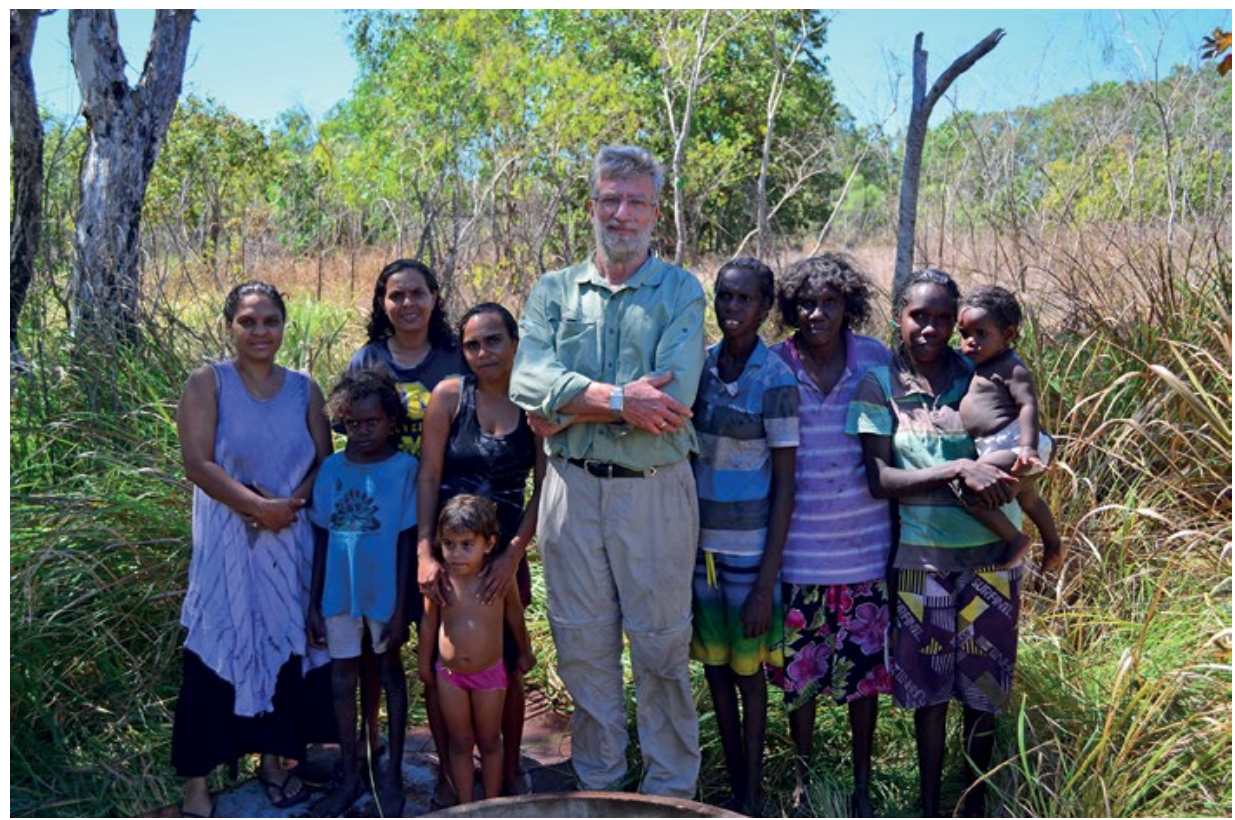

Figure 11.2 David Martin in 2014 at the Kuchenteypenh Well with a group of younger Wik from Kendall River families, seeing their country for the first time.

Photo: Rex Martin

It is this role as conduit, bringing in new information and ideas, coupled with APN's ability to engage employees at various levels - full-time, part-time, casual/seasonal - to perform the work required, that has allowed APN to have some success in Aurukun. Indigenous ranger programs across the country are perfect examples of investment that creates benefit for all Australians, through managing large areas of critical biodiversity, but also linking to localised 
aspirations and Indigenous cultural practices. This investment is, however, heavily dependent on government funding and therefore at risk due to the political cycle. For this reason, Wik people articulated the critical need to have a diversity of enterprises that were built on market economics. We engaged our membership and described this diversification of revenue streams as being like the mosaic pattern of traditional burning. APN's long-term goal is to help establish a mosaic of livelihoods and subsequent entry points for Wik people, so that they are able to engage in relation to their own skill levels and interests, and for the period to which they are willing and able to commit.

Much like APN's need to have diversity in income and therefore mitigate risk, to be truly sustainable there needed to be a diversification of income streams at both family and outstation levels. One family member might work for the cattle operation, another for the rangers, there might be some family over a dry season that collects seeds as part of Rio Tinto Alcan Weipa's revegetation program (an Aurukun community resident working in this program made a taxable income of $\$ 45,000$ in the 2013 dry season, logistically assisted by APN), the station as a whole might wish to participate in the native honey industry and there is the potential for small-scale carbon abatement credits, the potential for aquaculture and myriad other economic activities. The key message APN continues to push through the work it does in Aurukun is that, in the twenty-first century, greater economic independence is true empowerment. This means reforming Wik people's perceptions of work and welfare. Our community organisation needs to lead by example by reducing our organisational dependency on government. That is easier said than done.

The aim of APN is ultimately to create a variety of opportunities that will allow different people, with different skill sets, abilities and aspirations, to engage in meaningful, productive activities, especially those based on country. The strength of these sorts of programs, as I see it, is that they cater to people with those various levels of ability and understandings of work. Take someone who has only ever had the experience of CDEP or two days a week work-for-thedole; it is unreasonable to expect them to manage a five-day week performing fairly rigorous work from the outset. A perfect example of this was in 2012 when we needed to do $47 \mathrm{~km}$ of fencing leading up to Christmas between the Kirke and Love rivers to help muster and truck out cattle. We had roughly six weeks to do this work. APN went through 46 casual workers during this six-week period; eight were offered full-time work starting the next year. Of the eight, four are still working for APN.

Earlier in this chapter, during his experiences in the 1970s and 1980s, David wrote of the ways in which Wik people realised their 'agency through dependency'. Through my own experiences, I found this to be true in the period from 2010 to 2014 in the work I did with APN. There seemed to be an incapacity 
and general unwillingness to take personal responsibility for even menial tasks and deliverables. Even senior rangers avoided requesting or directing others to perform work-related tasks, due to the impact this might have on interfamily relations. Much like my father in the 1970s at Kendall River and with the Outstation Support Group, I often found myself being made responsible for matters that required cross-family cooperation. Wik people who are truly within the Wik kin, cultural and political system find it highly problematic to engage across family and clan groups. This was not only an issue within the workforce, but was also particularly apparent when family put pressure on individuals to utilise company assets. The demands were often around using a ranger's time and APN vehicles to drive family out hunting or to take boats out fishing; the demands were incessant. At a critical start-up and growth phase for the organisation, these pressures could ultimately affect the companies' ability to deliver on contracts and to manage works within a budget. At the individual level, the demands on some employees during APN's fortnightly pay cycle were enough to make them quit, with one young ranger having to give up his hard-earned pay to close kin, some of whom had threatened him with violence. For him, the easier option seemed to go back into the system everyone else was in.

To me at least, it seemed that 30 years of CDEP and the new policy paradigm, Remote Jobs and Community Program (RJCP), are the destination rather than a transitionary program, and 30 years of relaxed expectations of what constituted a full day's productive work for the Aurukun Shire Council has meant that many younger generations of Wik have low expectations of themselves around work. It is this enculturation into a relaxed work ethic that has become a major barrier for many Wik people seeking more mainstream employment.

There were of course the exceptions, and in the APN experience these were a few older men who were respected for their knowledge of culture, ceremony and country. However, both of these senior men had experiences during the mission era of working outside the Aurukun community, on pastoral properties around Queensland and even in the logging industry in Papua New Guinea. Ultimately, this 'agency through dependency' has created a wicked dependency on agencies in Aurukun, both government and regional organisations. A by-product of this is that it has in turn inadvertently disempowered Wik people from being critical players in the decision-making processes within Aurukun. The other by-product is that the process has totally alienated an unskilled younger generation that has neither the deep cultural knowledge nor the ability to work between two worlds, which the Aurukun Mission previously supported.

The key strength in APN during the initial engagement, incorporation and early operations phases centred on governance. It was the approach pushed by key elders in those early days that, rather than be auspiced by an external entity 
to attract funding quicker and get programs happening sooner, we needed to concentrate on creating our own vehicle to achieve our own ends. The decisionmaking structures and accountability systems that were created were developed internally, Wik owned and led, but with external advice. Although there were mistakes and lessons along the way, it was a critical process as it created a mandate and therefore legitimacy in the decision-making.

\section{Conclusion: What does the Wik experience say about 'self-determination'?}

Here, we limit our conclusions to the Wik situation; we have not as yet given sufficient thought to whether they can be generalised beyond it. David Martin's 1970s understanding of 'self-determination' was that it entailed Wik people running their own affairs in a form of cultural and political autonomy, and that his role was to work collaboratively with them towards this end, and indeed under their ultimate direction. As he outlined it previously, his obligation was to 'work himself out of a job'. He was drawn into supporting the outstation movement in Aurukun, initially through personal connections with the Kendall River people and then more broadly, because it seemed clear to him that it was an expression of the desire of those Wik people for self-determination. The desire to be supported to move 'back to country' was strongly expressed (and to some extent, among some older Wik people, still is). We are of the view that there continue to be at least three compelling but largely pragmatic arguments pragmatic in the sense of not having to rely on arguments for Aboriginal rights, important though these are - to support Wik people maintaining close connections to traditional lands.

The first concerns the imperative for the development of a mixed or 'hybrid' economy (Altman 2005) for Aurukun, which now has a working-age Wik population of perhaps 400 people but very low employment. In such situations, livelihoods on country of the kind being instituted across northern Australia, including in the Aurukun region through the work of APN, provide an important avenue for socially meaningful and productive employment. However, the APN experience demonstrates that only a small proportion of the working-age population - probably less than 10 per cent - can be involved in working on country, which, if sole reliance on welfare payments is to be avoided, suggests there needs also to be a substantial parallel move for many to engage with the market and state-subsidised economic sectors.

The second argument, and one linked to the above, concerns the involvement of Wik people themselves in the management and enhancement of a landscape that is of considerable national significance in terms of its biodiversity, through 
the provision of environmental services, carbon farming and the like. However, while the philanthropic and private sectors are investing in this arena, its sustainability is heavily dependent on government funding, and current political and economic circumstances suggest that this will be increasingly under threat.

The third argument centres on the significance of country to the transmission of central elements of distinctive Wik culture to future generations - and thereby also to the management and transmission of elements of a locally and nationally significant cultural landscape. For this culture to involve more than increasingly essentialised forms that are divorced from the realities of people's everyday experience, it is critical that there is a core of Wik people actively involved in gaining livelihoods on country, as well as those (visiting kin and so on) who orbit between Aurukun and outstations.

Each of these three elements would necessarily entail profound individual and collective transformation, and would require in particular significant changes in the dispositions and practices of Wik people - especially upcoming generations of Wik men - around the nexus between work and more generally productive activity on the one hand, and value and reward on the other. However, our own experiences in the Aurukun region spanning nearly four decades would suggest that there has been entrenched resistance to such transformations, or if not active resistance, certainly a pervasive unwillingness or an incapacity to change. Furthermore, any potential for 'working on country' and other such government programs to resource social transformation around these matters has been completely undermined by a lack of long-term commitments in funding and shifts in policy driven by ideological fads.

Finally, the twenty-first century is making new demands on the old thinking underlying outstations as manifestations of people wishing to run their own affairs in their own way. In the earlier period of David Martin's engagement with Aurukun, he gave little intellectual attention to what Wik people themselves variously saw as significant in 'their own affairs' or what they actually wished or were willing to manage themselves, or to how his own role might be understood, or more broadly to the interrelationship between 'their affairs' and matters arising from Wik people's interaction with the institutions of the wider society.

We suggest that 'self-determination', at least in the ways the term was used in the 1970s and 1980s, is best understood as shorthand for particular ideological and sometimes essentialised representations of Aboriginal agency, individually and collectively, and of the relationship between that agency and the engagement of Aboriginal people with the broader Australian society. 'Self-determination' has historically been determinedly focused on the collective Aboriginal group or community - here Wik people, for example, or the 'community' of Aurukun. 
It leaves unexamined the critical role that individuals play in social change (of whatever kind), and assumes that it proceeds by some sort of consensus or collective agreement to a course of action within the group in question. However, we have come to the view that Wik agency, manifested in what we have termed 'agency through dependency', required and requires outsiders, or even better 'insider-outsiders' (such as Bruce Martin) and 'outsider-insiders' (such as Peter Sutton and David Martin), for the achievement of certain purposes, both internal (so to speak) to Wik society and relating to its engagement with the broader society. This is far from a novel argument more generally: in matters concerning Aboriginal health, it has long been proposed that doctors can be agents of social change (Cawte and Kamien 1974; Brady 2000), in part because, as Brady (2000: 8) puts it, they are an authorising 'other', a person who is outside the individual's immediate kin network and who can legitimate the transformation of particular behaviours (see Sutton 2001: 150).

And how could it be any other way? If we accept the thrust of the notion of Aboriginal life-worlds as constituting 'intercultural' social fields proffered in the Australian context by Merlan (1998) and Hinkson and Smith (2005) and others (for example, Martin 2003), it is no longer defensible to think, or act, in terms of a supposedly separate Aboriginal domain, Wik or otherwise. An inescapable consequence therefore is that social transformation requires 'brokers' or 'change agents' or 'social entrepreneurs' (to use common terminology) who are adept across the diverse repertoires to be found in these intercultural fields.

And this is never more the case than in contemporary Aurukun, where living and working on country are not in any meaningful way to be seen as revitalisation of some traditional world, but are absolutely a transformative project: multiple new skills, many drawing on modern technologies; working collaboratively with other Wik and with non-Wik and engaging in productive activities that serve common goals rather than aimless self-aggrandisement; structured time allocation; having regard to scarce resources; and more generally transformed ways of being and acting in the world that resonate with those of the classical past but are not limited to them.

\section{References}

Altman, J. C. 2005. Development options on Aboriginal land: Sustainable Indigenous hybrid economies in the twenty-first century. In L. Taylor, G. Ward, G. Henderson, R. Davis and L. Wallis (eds), The Power of Knowledge, the Resonance of Tradition. Canberra: Aboriginal Studies Press, pp. 34-8. 
Brady, M. 2000. Introducing brief interventions for Indigenous alcohol misuse: Can doctors make a difference? Paper presented at Australian Institute of Aboriginal and Torres Strait Islander Studies Seminar, Canberra, 18 September.

Cawte, J. and Kamien, M. 1974. The doctor as a social change agent in Bourke, NSW. In B. S. Hetzel, M. Dobbin, L. Lippmann and E. Egglestone (eds), Better Health for Aborigines (Report of a National Seminar at Monash University). Brisbane: University of Queensland Press, pp. 151-60.

Gerritsen, R. 1982. Outstations, differing interpretations and policy implications. In P. Loveday (ed.), Service Delivery to Outstations. Monograph. Darwin: North Australia Research Unit.

Hinkson, M. and Smith, B. 2005. Introduction: Conceptual moves towards an intercultural analysis. Oceania 75(3): 157-66.

Martin, D. F. 1988. Background paper on social and family factors for the Aurukun case. Report to the Royal Commission into Aboriginal Deaths in Custody, November 1988.

Martin, D. F. 1993. Autonomy and relatedness: An ethnography of Wik people of Aurukun, western Cape York Peninsula. Unpublished PhD thesis. The Australian National University, Canberra.

Martin, D. F. 2003. Rethinking the design of Indigenous organisations: The need for strategic engagement. CAEPR Discussion Paper No. 248. Canberra: Centre for Aboriginal Economic Policy Research.

Martin, D. F. 2009. Domesticating violence: Homicide among remote dwelling Australian Aboriginal people. In Domestic-related homicide: Keynote papers from the 2008 international conference on homicide. AIC Report No. 104, Research and Public Policy Series. Canberra: Australian Institute of Criminology.

Martin, D. F. 2010. The art of Wik politics and the politics of Wik art. In S. Butler (ed.), Before Time Today, Reinventing Tradition in Aurukun Aboriginal Art. Brisbane: University of Queensland Press, pp. 118-31.

Martin, D. F. 2011. Policy alchemy and the magical transformation of Aboriginal society. In Y. Musharbash and M. Barber (eds), Ethnography and the Production of Anthropological Knowledge: Essays in Honour of Nicolas Peterson. Canberra: ANU E Press, pp. 201-15.

Merlan, F. 1998. Caging the Rainbow: Place, Politics, and Aborigines in a North Australian Town. Honolulu: University of Hawaii Press. 
Peterson, N. 1993. Demand sharing: Reciprocity and the pressure for generosity among foragers. American Anthro 954: 860-74.

Sutton, P. 1978. Wik: Aboriginal society, territory and language at Cape Keerweer, Cape York Peninsula Australia. Unpublished PhD thesis. University of Queensland, Brisbane.

Sutton, P. 2001. The politics of suffering: Indigenous policy in Australia since the 1970s. Anthropological Forum 11(2): 125-73.

Sutton, P. 2009. The Politics of Suffering: Indigenous Australia and the End of the Liberal Consensus. Melbourne: Melbourne University Press.

Sutton, P., Martin, D. F., von Sturmer, J., Cribb, R. and Chase, A. 1990. AAK: Aboriginal Estates and Clans between the Embley and Edward Rivers, Cape York Peninsula. Adelaide: South Australian Museum. 
This text is taken from Experiments in self-determination: Histories of the outstation movement in Australia, edited by Nicolas Peterson and Fred Myers, published 2016 by ANU Press, The Australian National University, Canberra, Australia. 